\title{
Liner sailing speed optimization considering wind and waves
}

\author{
Zhaokun Wei \\ College of Transportation, Shandong University of Science and Technology, Qingdao, China, \\ wzkskd_2018@sdust.edu.cn \\ Xinlian Xie \\ College of Transportation Engineering, Dalian Maritime University, Dalian, China \\ Tiantian Bao \\ Faculty of Maritime and Transportation, Ningbo University, Ningbo, China
}

Follow this and additional works at: https://jmstt.ntou.edu.tw/journal

3 Part of the Fresh Water Studies Commons, Marine Biology Commons, Ocean Engineering Commons, Oceanography Commons, and the Other Oceanography and Atmospheric Sciences and Meteorology Commons

\section{Recommended Citation}

Wei, Zhaokun; Xie, Xinlian; and Bao, Tiantian (2021) "Liner sailing speed optimization considering wind and waves," Journal of Marine Science and Technology. Vol. 29: Iss. 3, Article 15.

DOI: $10.51400 / 2709-6998.1469$

Available at: https://jmstt.ntou.edu.tw/journal/vol29/iss3/15

This Research Article is brought to you for free and open access by Journal of Marine Science and Technology. It has been accepted for inclusion in Journal of Marine Science and Technology by an authorized editor of Journal of Marine Science and Technology. 


\title{
RESEARCH ARTICLE
}

\section{Liner Sailing Speed Optimization Considering Wind and Waves}

\author{
Zhaokun Wei ${ }^{\mathrm{a}, *}$, Xinlian Xie ${ }^{\mathrm{b}}$, Tiantian Bao ${ }^{\mathrm{c}}$ \\ ${ }^{\text {a }}$ College of Transportation, Shandong University of Science and Technology, Qingdao, China \\ ${ }^{\mathrm{b}}$ College of Transportation Engineering, Dalian Maritime University, Dalian, China \\ ${ }^{\mathrm{c}}$ Faculty of Maritime and Transportation, Ningbo University, Ningbo, China
}

\begin{abstract}
This paper proposes a new sailing speed optimization problem considering sea conditions such as wind and waves for a container shipping company. Since wind and waves, as exterior factors, can reduce speed, more power is employed as compensation to maintain regular service frequency and avoid delay, resulting in additional bunker consumption and higher cost. Hence, it is necessary to optimize the sailing speed according to the wind and waves. A power model was built to determine the reduced speed caused by the wind and waves for quantifying the speed reduction. On the basis of the proposed model, we developed a mixed-integer nonlinear programming model for a sailing speed optimization problem considering the wind and waves. In view of the complexity of the function for determining the speed reduction, a discrete method is proposed to transform the proposed mixed-integer nonlinear programming model into a mixedinteger linear programming model. Finally, a numerical experiment was conducted to verify and validate the applicability.
\end{abstract}

Keywords: Container liner shipping, Sailing speed optimization, Wind and waves, Speed reduction

\section{Introduction}

$\mathrm{M}$ aritime transport is the backbone of globalization and lies at the heart of crossborder transport networks that support supply chains and enable international trade. Container shipping is a representative example. In 2015, the total containerized trade volume was estimated to be 1.69 billion tons, equivalent to 175 million twenty-foot equivalent units (TEUs) [28]. A container shipping company as an economic entity aims to maximize its interests. It is favourable to increase the number of laden containers transported from origin ports to destination ports through the shipping network with lower operating costs. In other words, the maximum return is determined by the operating cost and revenues.
In general, the operating cost mainly consists of the fixed cost and variable costs. The fixed cost is composed of the maintenance cost, salaries of the crews, and insurance, among other components, and is often assumed to be constant because a constant rotation of ports is included in a shipping route and because a schedule is determined beforehand to maintain the fixed service frequency. The container handling cost and bunker fuel consumption cost during the voyage are included in the variable costs. The bunker consumption cost is a large proportion of the total operating cost [25]. When the crude oil price is high, the estimated bunker cost can exceed $60 \%$ of the operating cost [7].

The bunker consumption cost is determined mainly by the sailing speed, and the sailing speed is 
affected by the wind and waves. When the sea conditions are severe, more power is employed to overcome the speed reduction caused by wind and waves to maintain the sailing speed and regular schedule. Typically, speed reduction results from resistance, composed of basic resistance and added resistance. Basic resistance refers to frictional resistance and residual resistance. Added resistance includes wind loads and wave-added resistance, for example. These resistances are affected by the ship dimensions and can be estimated through shipmodel testing. Different ship dimensions can result in different speed reductions in the same situation [14]. With an increase in bunker consumption costs caused by employing more power, determining the appropriate sailing speed is a key challenge to maintain a regular schedule and decrease the additional costs caused by employing more power. Thus, determining the liner sailing speed considering the wind and waves is meaningful for liner companies to reduce operating costs from the operational level. The round-trip time of a shipping route is affected by the sailing speed. For example, if the sailing speed is 24 knots, then the round-trip time of a container ship is 56 days. However, the round-trip time might reach up to 63 days with a lower speed. As liner shipping companies supply weekly shipping service, the number of container ships deployed on the shipping route increases with slows steaming. Our research focuses on determining the appropriate sailing speed considering the wind and waves to maintain a regular service frequency while lowering the cost. The following two vital decisions must be made to solve our proposed problem.

(i) (Speed reduction) What is the scale of speed reduction? Various sea conditions and ship courses can result in different scales of speed reduction for a constant sailing speed. Determining the speed reduction is of use when determining the actual sailing speed over ground and estimating bunker consumption.

(ii) (Liner ship speed optimization) What is the sailing speed of a container ship on each leg during the voyage? Although more power can overcome speed reduction, the use of more power also results in a bunker consumption cost increase. If more power is not employed, it may be necessary to violate a predetermined schedule or deploy more ships, resulting in a cost increase. Therefore, it is essential to determine the appropriate sailing speed on every leg that maintains a regular service frequency while minimizing bunker consumption.
Here, we propose an optimization model and an effective solution method for solving container ship sailing speed optimization problems considering the wind and waves. The two key questions, speed reduction and sailing speed optimization, are addressed in this study because they are intrinsically interrelated in practice. We apply an efficient guide to determine the operational management measures for container liner shipping companies facing complex and varying sea conditions.

\subsection{Literature review}

Multiple studies have focused on sailing speed optimization [2,20,24] developed an optimization model to determine the optimal uniform sailing speed on a single voyage $[4,32]$. Jointly addressed the berth allocation and sailing speed [23,29,30]. Solved a schedule design problem taking the choice of speed into consideration [31]. Proposed a model to achieve the optimal speed on each voyage leg in a liner shipping network [13,26,33,38]. Simultaneously optimized sailing speed and bunking strategies [34]. Incorporated sailing speed optimization into seasonal shipping revenue management [1]. Developed a speed optimization model with stochastic port times and time windows [15]. Proposed a dynamic sailing speed optimization model for real-time recovery under various regular uncertainties and disruption events to recover the predetermined schedule in the most efficient way $[6,10,21]$, focused mainly on the sailing speed for tramp ships.

Some studies have assumed that the sailing speed is constant $[3,8,9,17,18,27,35-37]$ and others have assumed that bunker consumption is proportional to the third power of the sailing speed according to engine theory and empirical data $[2,16,19,24,31,33,34]$. However, few studies have quantified the effects of wind and waves on bunker consumption and the sailing speed for liner shipping. Although [14] proposed a speed decision model by establishing a real fuel consumption function that considers the effects of wind and current based on weather archive data, their established consumption function is just a relational expression according to the weather archive data and fuel consumption record. In other words, it cannot quantify the specific speed reduction and fuel consumption when only sea states are provided. In general, more laden containers loaded on the deck imply a larger wind area than with other ship types, which degrade the propulsion efficiency. When a containership sails in water, wave-added resistance (idealized as a resultant second-order nonlinear force) can increase the challenges 
associated with maintaining the desired sailing speed. Speed reduction caused by wind and waves may result in a longer sailing time, requiring the deployment of more containerships on the voyage to guarantee service frequency or requiring additional thrust power. In any case, deploying more containerships or employing more thrust power tends to increase costs. It is essential to determine the appropriate sailing speed to maximize revenue with quantifying the effects of the wind and waves on the sailing speed and fuel consumption. To the best of our knowledge, there have been no previous studies to provide this information. The present study develops a speed reduction model incorporating the effect of wind and waves to estimate a change in the sailing speed under various sea conditions. On the basis of the model, we propose a sailing speed optimization model that considers wind and waves to overcome the limitations discussed above.

\subsection{Objectives and contributions}

The purpose of this research is to investigate the problem of the optimization of the sailing speed of container ships, quantifying the effects of wind and waves on the sailing speed and fuel consumption, with the objective of maximizing the container liner shipping company profit for a specific ship type deployed over a shipping network. The freight revenue is assumed to be the major income of the container liner shipping company, and the operational costs, composed of the variable part (i.e., the bunker consumption cost and container handling cost) and the fixed part (i.e., the containership fleet operational cost) are the total expenditure. Therefore, the proposed model should determine the most profitable number of containers to be transported between ports over a shipping network subject to the volume constraints of containerships. We also consider that different sailing speeds should be selected on different sailing legs in accordance with the containership course, wind and wave directions and containership dimensions to reduce the bunker consumption cost. Finally, an optimal fleet size should be determined that maintains a regular service frequency while meeting the transport demand. We emphasize that the fleet mix issue is not considered. The purpose is to determine the appropriate sailing speed under given conditions of the wind and waves, in which the demand between origin ports and destinations can be hypothesized to be constant.

In terms of the bunker consumption, the output power is adopted to estimate the bunker consumption with different sailing speeds due to the complexity of the relationship between the thrust power and bunker consumption. The proposed sailing speed optimization problem considering wind and waves is formulated as a mixedinteger nonlinear programming (MINLP) model. A discrete method is designed to transform the MINLP model into a mixed-integer linear programming (MILP) model to make use of state-of-art mixed-integer linear programming solvers, which reduces the computational load and solution complexity by simplifying the proposed model. Furthermore, numerical experiments are conducted to assess the applicability of the proposed model.

The contributions of this study are threefold. First, the proposed sailing speed optimization for the container liner shipping company is a new issue with widespread application value because it quantifies the effects of wind and waves on the sailing speed for determining the increase in bunker consumption caused by speed reduction. Second, a power model is designed to estimate the speed reduction caused by wind and waves. Third, on the basis of the proposed power model, an MINLP model is developed for the proposed sailing speed optimization problem. Finally, a linearization method is designed to transform MINLP into MILP.

This paper is organized as follows. Section 2 proposes a power model to estimate the speed reduction under the conditions of wind and waves. Section 3 provides assumptions, notation and a description of the sailing speed optimization considering wind and waves. Based on Section 3, an MINLP model is developed in Section 4. In Section 5 , we propose a discrete method transforming MINLP into MILP. Numerical experiments are described in Section 6 to verify the application of the developed model. Finally, conclusions are presented in Section 7.

\section{Estimating the speed reduction using the model}

The operability of the ships can be affected by various sea conditions. In particular, the resistance of the ships should be taken into consideration to maintain the ship operational efficiency. In terms of containerships, more resistance implies that more power is needed to maintain a fixed sailing speed. In other words, more resistance causes speed reduction if more power is not employed. To determine the optimal sailing speed, a reliable method is required to estimate the speed reduction under various sea conditions. The resistance is composed of the basic resistance and added resistance. The 
basic resistance includes the frictional resistance, residual resistance, eddy-making resistance and wave-making resistance. The added resistance includes the fouling resistance, appendage resistance, air resistance, rough water resistance and added shallow water resistance. Without loss of generality, the wind loads on a containership have an increasing effect on navigation with increasing containership sizes, and additional horse power is required to overcome wave added resistance and maintain the desired speed. Therefore, this study focuses on basic resistance, air resistance and rough water resistance.

\subsection{Basic resistance}

Basic resistance corresponds to the resistance to ship movement generated in calm water. In general, a ship-model resistance experiment is adopted to estimate the magnitude of this effect. According to similarity criteria, equations to calculate the basic resistance were suggested by Ref. [12] as follows:

$F_{R}=\frac{1}{2} \rho S C v^{2}$

$C=C_{f}+C_{r}+\Delta C$

where $\rho$ is the seawater density, $S$ is the wetted area, and $C$ is the resistance coefficient, comprised of the frictional resistance coefficient $\left(C_{f}\right)$, residual resistance coefficient $\left(C_{r}\right)$ and roughness subsidies coefficient $(\Delta C) . v$ is the sailing speed in calm water.

In theory, the wetted area is calculated by integral computation based on the ship form. Due to the lack of information regarding the ship form, equation (3) was suggested by Ref. [12] for calculating the wetted area.

$S=k \sqrt{\nabla L_{w}}$

where $\nabla$ is the volume of displacement, $L_{w}$ is the designed waterline length, and $k$ is the area coefficient and is a function of $C_{\mathrm{m}}$ (the midship section coefficient) and $B / d_{\mathrm{m}}$ ( $B$ is the ship width, and $d_{\mathrm{m}}$ is the ship draft). The so-called ITTC-57 equation is deployed for calculating the frictional resistance coefficient, as shown below.

$C_{f}=\frac{0.075}{(\lg R e-2.03)^{2}}$

where $R e$ is the Reynolds number. The residual resistance is composed of the wave-making resistance and eddy resistance. Both cannot be calculated accurately in theory. We are able only to estimate the values using the Lap-Keller chart, which refers to the sailing speed in calm water. The roughness subsidies coefficient is determined by the ship length. Different ship length ranges have different roughness subsidies coefficients, as described in Table 1.

\subsection{Wind loads}

[11] proposed equations for the calculation of wind loads that are typically used in ship hydrodynamics fields.

$X_{1}=\frac{1}{2} \rho_{a} A_{f} V_{R}^{2} C_{x}\left(\alpha_{R}\right)$

$Y_{1}=\frac{1}{2} \rho_{a} A_{s} V_{R}^{2} C_{y}\left(\alpha_{R}\right)$

$Z_{1}=\frac{1}{2} \rho_{a} A_{s} L V_{R}^{2} C_{z}\left(\alpha_{R}\right)$

where $X_{1}, Y_{1}$ and $Z_{1}$ denote the ahead force, side force and yaw moment, respectively. $C_{x}, C_{y}$ and $C_{z}$ are the drag coefficients of the wind forces and are functions of $\alpha_{R}$, which is the coefficient of the relative wind incident angle. $A_{f}$ and $A_{s}$ are the longitude and the lateral projected areas of the ship on the wetted area, respectively. The air density is denoted by $\rho_{a} . L$ is the ship length, and $V_{R}$ is the relative wind velocity determined by the apparent wind and the true wind.

\subsection{Wave-added resistance}

The wave-added resistance can be modelled as either a first-order or second-order force. We consider that the wave-added resistance is a firstorder force. Many methods have been proposed to calculate the wave-added resistance; however, these methods are not amenable to straightforward calculation in practical circumstances because the developed methods are relatively complex and the accuracy cannot meet engineering requirements. Hitherto, ship-model experiments are mainly employed for the calculation of the wave-added resistance. Generally, the equations developed by Daiodla [5] are suggested as follows:

Table 1. Values of $\Delta C$.

\begin{tabular}{|c|c|c|c|}
\hline Ship length (m) & $\Delta C$ & Ship length $(\mathrm{m})$ & $\Delta C$ \\
\hline $50-150$ & +0.0004 to +0.00035 & $260-300$ & 0 \\
\hline $150-210$ & +0.0002 & $300-350$ & -0.0001 \\
\hline $210-260$ & +0.0001 & $350-450$ & -0.00025 \\
\hline
\end{tabular}


$X_{2}=\frac{1}{2} \rho L a^{2} \cos \chi C_{x}^{1}(\lambda)$

$\Upsilon_{2}=\frac{1}{2} \rho L a^{2} \sin \chi C_{y}^{1}(\lambda)$

$Z_{2}=\frac{1}{2} \rho L^{2} a^{2} \sin \chi C_{z}^{1}(\lambda)$

where $X_{2}, Y_{2}$, and $Z_{2}$ are the ahead drifting force, side drifting force and yaw moment, respectively. $L$ is the ship length, $a$ is the wave amplitude, $\chi$ is the encounter angle, $\lambda$ is the wave length, and $C_{x}^{1}, C_{y}^{1}$, and $C_{z}^{1}$ are coefficients determined by $\lambda$ and $L$, as shown below.

$$
\begin{aligned}
& C_{x}^{1}=0.05-0.2\left(\frac{\lambda}{L}\right)+0.75\left(\frac{\lambda}{L}\right)^{2}-0.51\left(\frac{\lambda}{L}\right)^{3} \\
& C_{y}^{1}=0.46+6.83\left(\frac{\lambda}{L}\right)-15.65\left(\frac{\lambda}{L}\right)^{2}+8.44\left(\frac{\lambda}{L}\right)^{3} \\
& C_{z}=-0.11+0.68\left(\frac{\lambda}{L}\right)-0.79\left(\frac{\lambda}{L}\right)^{2}+0.21\left(\frac{\lambda}{L}\right)^{3}
\end{aligned}
$$

\subsection{Speed reduction model}

In general, the speed of a self-propelled ship in calm water is determined by the intersection of the effective thrust line and resistance line, and this approach is typically used to determine the speed as governed by the total resistance. However, there are some challenges associated with the ship speed and rapid alteration of the course. The total resistance is different in different sea conditions. Even if the sea conditions are the same, the total resistance is dependent on the course. We must make use of the effective thrust curve and the total resistance to determine the reduced speed $v_{r}$ by finding the intersection of these two lines.

We assume that the speed reduction caused by the wind and waves in this study is limited. Therefore, it is appropriate to assume that the effective power $P_{e}$ remains constant in the applicable range of speed reduction from speed $v$ in calm water to the reduced speed $v^{r}$, as described in Eq. (14).

$P_{e}=F_{T}\left(v^{r}\right) v^{r}$

According to the conversion of energy, the equation shown below is developed.

$F_{R}(v) v=F_{T}\left(v^{r}\right) v^{r}+F_{A}(v) v$

where $F_{R}$ is the calm water resistance, $F_{T}$ is the total resistance, and $F_{A}$ is the added resistance. Since the speed reduction is mainly caused by the forward force, $F_{A}$ is composed of $X_{1}$ and $X_{2}$.

Combining Eqs. (1), (5) and (8) with Eq. (15), the equations proposed as follows can be adopted to estimate the amount of speed reduction.

$\frac{1}{2} \rho S v^{3} C=\frac{1}{2} \rho S v^{r 3} C+F_{A}(v) v$

$v^{r}=\left(v^{3}-2 \frac{F_{A}(v) v}{\rho S C}\right)^{\frac{1}{3}}$

\section{Notation, assumptions and problem description}

To explain certain fundamental settings for the liner sailing speed optimization problem considering wind and waves, this section involves five aspects: the weekly service frequency and liner shipping network, the container routing with capacity constraints, the port time and sailing time during the voyage, the bunker fuel consumption function, and the objective of the sailing speed affected by the wind and wave problem.

\subsection{Liner shipping network and weekly service frequency}

We assume that a liner shipping network operated by a container liner shipping company is composed of numerous shipping routes. $R$ denotes the set of all shipping routes. We denote a shipping route by $r \in R$. A shipping route is essentially a loop with a sequence of port calls. $1 \rightarrow 2 \rightarrow \cdots \rightarrow i \rightarrow \cdots \rightarrow N_{r} \rightarrow 1$ can represent a shipping route, where number 1 is the first port call and $N_{r}$ is the last port call. $I_{r}=\left\{1,2, \cdots, N_{r}\right\}$ denotes the set grouped by all of those ports. A series of voyages between adjacent ports constitutes a shipping route $r \in R$. The voyage between adjacent ports is often called a shipping leg and is numbered according to the starting port call $i \in I_{r}$. However, shipping leg $i \in I_{r}$ also consists of a series of sub-shipping legs, as shown in Fig. 1. We denote the set of sub-shipping legs included in shipping leg $i \in I_{r}$ by $I_{r}^{i}=\left\{j \mid j \in I_{r}^{i}\right\}$. We take the subshipping legs into consideration to improve the accuracy of sailing speed optimization. For example, there are four sub-shipping legs included in the shipping leg between Qingdao Port and Dalian Port, as shown in Fig. 1. Therefore, containerships sailing on a different sub-shipping leg must adopt a different course. In addition, different courses imply different total resistance values. Therefore, it is reasonable to 


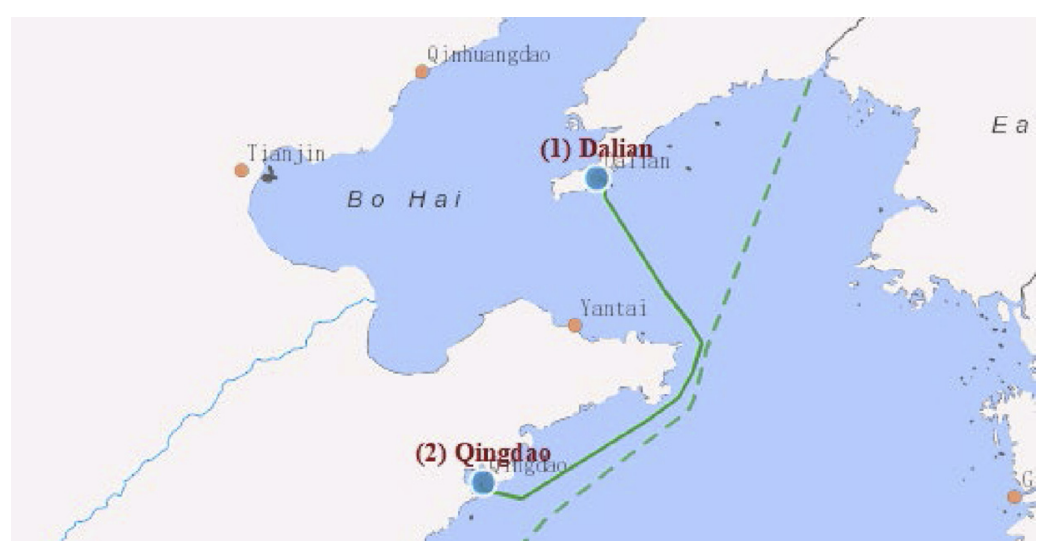

Fig. 1. Sub-shipping legs included in the shipping leg between Qingdao Port and Dalian Port.

select an appropriate sailing speed for various values of the total resistance. We assume in this study that ships of the same type with volume capacity Cap $r$ are deployed on the shipping route $r \in R$ to guarantee regular weekly service frequency. The total time over a round trip of shipping route $r$ consists of three components: the port time $t_{r i}^{p}$ at port call $i$, the sailing time $t_{r i j}^{s}$ on every sub-shipping leg $j$ included in shipping leg $i \in I_{r}$ and the total time spent by loading, unloading and trans-shipping container $t_{r h}^{\text {handle }}$ at involved ports on the shipping route $r$ through container route $h$. To maintain the weekly service, the number of ships deployed on the shipping route $r \in R$ can be calculated as follows:

$n_{r}=\frac{\sum_{i \in I_{r}} t_{r i}^{p}+\sum_{i \in I_{r j} \in I_{r}^{i}} t_{r i j}^{s}+\sum_{w \in W h \in H^{w}} \sum_{r h} t_{\text {handle }}}{168} \quad \forall r \in R$

\subsection{Container routing with capacity constraints}

Containers are transported through the liner shipping network from the origin ports to the destination. $W=\left\{(o, d) \mid o, d \in \cup_{r \in R} I_{r}\right\}$ is used to represent the set of origin-destination pairs for containers. A container route $w \in W=(o, d)$ between origin port $o$ and destination port $d$ may be a specific shipping route or may consist of many segments involving several shipping routes. When a container route is a combination of several shipping routes, the ports connecting different shipping routes are ports of trans-shipment. Trans-shipment operations can occur in these ports. More than one container route can be available for the OD pair $w \in$ $W$. We denote the set of container routes adopted by the liner shipping network designed by the container liner shipping company for OD pair $w \in$ $W$ by $H^{w}$, and $x_{h r i}$ as a binary parameter is used to describe the relationship between shipping leg $i \in I_{r}$ and container route $h \in H^{w}$. If container route $h \in H^{w}$ consists of shipping leg $i \in I_{r}$, then $x_{h r i}$ is 1 . Otherwise, $x_{h r i}$ is 0 . The liner shipping schedule is typically not changed over 3-4 months. It is reasonable to hypothesize that the OD pair $w \in W$ weekly ship demand $D_{w}$ is constant. If the variable $y_{h}$ is the number of containers transported through container route $h \in H^{w}$, then the following shipment demand constraint must be fulfilled.

$\sum_{h \in H^{w}} y_{h} \leq D_{w} \quad \forall w \in W$

$\sum_{w \in W h \in H^{w}} x_{h r i} y_{h} \leq \operatorname{Cap}_{r} \quad \forall r \in R, \quad i \in I_{r}$

where Capr is the volume capacity of the container ship deployed on ship route $r$. The left side of constraint (20) denotes the number of containers transported on the shipping leg $i \in I_{r}$.

\subsection{Sailing times, port times and schedule time during a shipping route}

The parameter $v_{r i j}$ is the sailing speed during subshipping leg $j \in I_{r}^{i}$ included in shipping leg $i \in I_{r}$. In practice, $v_{r i j}$ often has a lower limit $V_{\min }$ and an upper limit $V_{\text {max }}$. The lower limit is the smallest economic sailing speed, and the upper limit is determined by the maximum power of the container ship engine.

$V_{\min } \leq v_{r i j} \leq V_{\max }$

The sailing time $t_{r i j}^{s}$ spent on sub-shipping leg $j \in I_{r}^{i}$ included in shipping leg $i \in I_{r}$ can be determined by the sub-shipping leg length $L_{r i j}$ and the sailing speed $v_{r i j}$, as described in Eq. (22).

$t_{r i}^{s}=\sum_{j \in I_{r}^{i}} \frac{L_{r i j}}{v_{r i j}} \quad \forall r \in R, \quad i \in I_{r}$ 
The time spent on handling containers at each port cannot be ignored. We introduce the parameter $t_{r h}^{\text {Handle }}$ as the sum of the time spent loading, unloading or trans-shipping a container at involved ports on the shipping route $r$ through container route $h$. This parameter is 0 if the container route $h \in H^{w}$ is not composed of any segments of the shipping route $r \in R$. Eq. (23) is used to calculate the total handling time spent on transporting all containers on shipping route $r$.

$t_{r}^{\text {Handle }}=\sum_{w \in W h \in H^{w}} t_{r h}^{\text {Handle }} y_{h} \quad \forall r \in R$

Combining Eqs. (22) and (23) with Eq. (18) yields the following:

$\sum_{i \in I_{r}} \sum_{j \in I_{r}} \frac{L_{r i j}}{v_{r i j}^{r}}+\sum_{w \in W h \in H^{w}} \sum_{r h}^{\text {Handle }} y_{h}+\sum_{i \in I_{r}} t_{r i}^{P} \leq 168 n_{r}$

The container liner shipping company typically formulates the schedule in advance. Container ships are expected to follow the addressed schedule. If container ships do not arrive at the port at the specified time for that particular container route, the carriers must pay a penalty for compensating shippers, and additional transit time can also decrease shipment demand. It is necessary to guarantee that carriers cannot violate the set schedule.

$$
\begin{aligned}
& \sum_{j \in I_{r}} \frac{L_{r i j}}{v_{r i j}^{r}}+t_{d i}^{r} \leq T_{i+1}^{r} \quad \forall r \in R, i \in I_{r} \\
& t_{d i+1}^{r}=\sum_{j \in I_{r}^{i}} \frac{L_{r i j}}{v_{r i j}^{r}}+t_{d i}^{r}+\sum_{w \in W h \in H^{w}} \sum_{h r i}^{w} i_{r h}^{\text {handle }} y_{h} \\
& \quad+t_{r i+1}^{p} \quad \forall r \in R, i \in I_{r}
\end{aligned}
$$

where $v_{r i j}^{r}$ is the sailing speed in the wind and waves on sub-shipping leg $j$ included in shipping leg $I, t_{d i}^{r}$ is the departure time at port of call $i$ on shipping route $r, T_{i}^{r}$ is the arrival time determined by the schedule proposed by the container liner shipping company, and $\delta_{h r i}^{w}$ is a binary variable. If origin port $o$ or destination port $d$ is port $i$ or port $i+1$ on shipping route $r$ and if container route $h$ consists of shipping leg $i$ on shipping route $r, \delta_{h r i}^{w}$ is 1 . Otherwise, $\delta_{h r i}^{w}$ is 0 .

\subsection{Bunker consumption function}

According to previous studies, we assume that the sailing speed and bunker consumption have a power relationship [33]. Proposed that the bunker consumption rate is a function of the displacement and sailing speed. Although these proposed methods can estimate bunker consumption, speed reduction cannot be considered. In other words, the estimated bunker consumption is lower than the practical bunker consumption. To our knowledge, bunker consumption is related to the power generated by the main engine. High power implies more bunker consumption. Therefore, knowledge of the power is beneficial to calculate the bunker consumption. To facilitate calculation, we consider that the power of the main engine is used to generate thrust power and that no energy is lost.

$Q_{r i j}=s P_{r i j} \frac{L_{r i j}}{v_{r i j}^{r}}$

where $Q_{r i j}$ is the bunker consumption on sub-shipping leg $j$ included in shipping leg $i, P_{r i j}$ is the power generated on sub-shipping leg $j$ included in shipping leg $i$, and $s$ is a coefficient in accordance with ISO. The right-hand-side term $\frac{L_{r i j}}{v^{r}}$ is the sailing time. $P_{r i j} \underline{v}_{r i j}^{r i j}$ is the work capacity of the main engine, and the work capacity of the main engine is transformed into bunker consumption by coefficient $s$.

\subsection{Objective of the sailing speed optimization problem considering the wind and waves}

The freight revenue obtained by transporting containers composes the major income of the shipping company. The shipping company must also pay for handling containers, bunker and fleet operation. Since it is assumed that the demand is unchanged, maximizing the total weekly profit ultimately maximizes the total profit. Thus, the operating cost, weekly freight revenue and total profit attract our attention.

The formulations of the operating cost and freight revenue are given first. The weekly freight revenue is calculated by multiplying the freight rate $p_{h}$ of containers for all OD port pairs by the number of containers transported.

$$
\sum_{w \in W h \in H^{w}} y_{h} p_{h}
$$

The operating costs are composed of two components: the fixed part and the variable part. The fixed part is related to fleet operation, which has nothing to do with containers. The variable part consists of the handling cost and bunker consumption cost depending on the number of containers transported. We denote the weekly operation cost of one ship deployed on shipping route $r$ by $C_{r}^{f i x}$, 
including the weekly containership maintenance cost and the salary of the crew per week, among other components. The weekly fleet operation cost is expressed as:

$\sum_{r} C_{r}^{f i x} n_{r}$

Loading, unloading and trans-shipping containers at ports on a container route can incur corresponding costs. To facilitate calculation, we define $C_{h}^{\text {Handle }}$ as the handling cost spent on loading, unloading and trans-shipping containers on container route $h$ to transport one container from its origin port to the destination port. Then, the weekly container handling cost can be expressed as:

$\sum_{w \in W h \in H^{w}} C_{h}^{\text {Handle }} y_{h}$

The weekly bunker consumption cost can be calculated as shown below.

$\beta \sum_{r \in R} \sum_{i \in I_{r}} \sum_{j \in I_{r}^{i}} s P_{r i j} \frac{L_{r i j}}{v_{r i j}^{r}}$

$P_{r i j}=\frac{1}{2} \rho S C v_{r i j}^{2} v_{r i j}^{r}$

where $\beta$ is the bunker price and $v_{r i j}$ is the sailing speed in calm water during sub-shipping leg $j$ included in shipping leg $i$. Substituting (32) into (31), the weekly bunker consumption can be expressed as:

$\frac{1}{2} \beta \sum_{r \in R} \sum_{i \in I_{r}} \sum_{j \in I_{r}^{i}} s \rho S C v_{r i j}^{2} L_{r i j}$

As described above, the weekly profit can be calculated as the total revenue minus total cost, i.e.,

$$
\begin{gathered}
F(N, V, Y)=\sum_{w \in W h \in H^{w}} \sum_{h} y_{h}-\beta \sum_{r \in R} \sum_{i \in I_{r}} \sum_{j \in I_{r}^{i}} s P_{r i j} \frac{L_{r i j}}{v_{r i j}^{r}} \\
-\sum_{r} C_{r}^{f i x} n_{r}-\sum_{w \in W h \in H^{w}} \sum_{h} C_{h}^{\text {Handle }} y_{h}
\end{gathered}
$$

where $N, V$, and $Y$ are variable vectors, namely, $N=$ $\left\{n_{r} \mid r \in R\right\}, V=\left\{v_{r i j} \mid j \in I_{r}^{i}, i \in I_{r}, r \in R\right\}$, and $Y=$ $\left\{y_{h} \mid w \in W, h \in H^{w}\right\}$, respectively. In Eq. (34), the first item refers to the freight revenue, the second item refers to the bunker consumption cost, the third item refers to the weekly operation cost, and the last item refers to the container handling cost.

The sailing speed optimization problem considering the wind and waves can be considered to determine the optimal value of decision variables $v_{r i j}, \forall r \in R, i \in I_{r}, j \in I_{r}^{i}, n_{r}, \forall r \in R$ and $y_{h}, \forall w \in W, \forall$ $h \in H^{w}$ to maximize profit.

\section{Mixed-integer nonlinear programming model}

On the basis of the analysis in Section 3, the proposed sailing speed optimization problem considering wind and waves can be formulated as an MINLP model.

$[M I N L P]$

$\max _{N, V, Y} F(N, V, Y)$

subject to

$\sum_{i \in I_{r}} \sum_{j \in I_{r}^{i}} \frac{L_{r i j}}{v_{r i j}^{r}}+\sum_{w \in W h \in H^{w}} \sum_{r h}^{\text {Handle }} y_{h}+\sum_{i \in I_{r}} t_{r i}^{P} \leq 168 n_{r} \quad \forall r \in R$

$\sum_{h \in H^{w}} y_{h} \leq D_{w} \quad \forall w \in W$

$\sum_{w \in W h \in H^{w}} x_{h r i} y_{h} \leq \operatorname{Cap}_{r} \quad \forall r \in R, \quad i \in I_{r}$

$\sum_{j \in I_{r}^{i}} \frac{L_{r i j}}{v_{r i j}^{r}}+t_{d i}^{r} \leq T_{i+1}^{r} \quad \forall r \in R, i \in I_{r}$

$$
\begin{aligned}
& t_{d i+1}^{r}=\sum_{j \in I_{r}^{i}} \frac{L_{r i j}}{v_{r i j}^{r}}+t_{d i}^{r}+\sum_{w \in W h \in H^{w}} \sum_{h r i} \delta_{r h}^{w} t_{r a n d l e} y_{h} \\
& \quad+t_{r i+1}^{p} \quad \forall r \in R, i \in I_{r}
\end{aligned}
$$

$P_{r i j}=\frac{1}{2} \rho S C v_{r i j}^{2} v_{r i j}^{r} \quad \forall r \in R, i \in I_{r}, j \in I_{r}^{i}$

$v_{r i j}^{r}=\left(v_{r i j}^{3}-2 \frac{F_{A}\left(v_{r i j}\right) v_{r i j}}{\rho S C}\right)^{\frac{1}{3}} \quad \forall r \in R, i \in I_{r}, j \in I_{r}^{i}$

$V_{\min } \leq v_{r i j} \leq V_{\max } \quad \forall r \in R, i \in I_{r}, j \in I_{r}^{i}$

$y_{h} \geq 0$

$n_{r} \in Z^{+}$

where the objective function (35) is to maximize the weekly profit. Constraint (36) is suggested to meet the weekly service requirement. Constraint (37) is set to guarantee that the number of containers transported for OD pairs cannot exceed the shipment demand between OD pairs. Constraint (38) imposes the volume capacity constraint. Constraints (39) and (40) avoid violating the shipping schedule. Constraint (41) calculates the engine power to estimate bunker consumption. Constraint 
calculates the sailing speed in the wind and waves. Constraint (43) provides the lower and upper limits of the sailing speed. Constraints (44) and (45) specify the domain of the decision variables.

Proposition 1. There is an optimal solution to the proposed model.

Proof. As constraints (36)-(45) do not include " $<$ " or ">", the domain of the proposed model is closed. All decision variables are bound. The domain of the proposed model is a compact set. Since all feasible solutions cannot be 0 , the domain is also nonempty. Moreover, the objective function is continuous. On the basis of the above analysis, there is an optimal solution for the proposed model.

\section{Equivalent MILP model}

The sailing speed optimization considering the wind and waves model developed in Section 4 is a mixed-integer nonlinear optimization model. Constraints (36), (39), and (40) and the second item in the objective function are nonlinear. An equivalent MILP model is proposed by linearizing the nonlinear items. To do so, we first take the sailing speed in calm water as 0.1 knot. When the conditions of the wind and waves are specified, every discrete sailing speed in calm water has a corresponding sailing speed in the wind and waves according to Eq. (17). The problem is transformed into selecting the optimal sailing speed in the wind and waves from the discrete sailing speed. Then, $U_{r i j}^{n}$, $X_{r i j}^{n}, Y_{r i j}^{n}$ and $b_{r i j}^{n}$ are introduced as auxiliary variables. The auxiliary variables are defined as follows:

$U_{r i j}^{n}=\frac{1}{v_{r i j n}^{r}}$

where $v_{r i j n}^{r}$ is the $n$th discrete sailing speed in the wind and waves, and the corresponding sailing speed in the calm water is $v_{r i j n} . U_{r i j}^{n}$ is the reciprocal of the sailing speed $v_{r i j n}^{r}$ in the wind and waves, and $b_{r i j}^{n}$ is a decision variable. If the $n$th discrete sailing speed during subshipping leg $j$ included in shipping leg $i$ on container route $r$ is selected, $b_{r i j}^{n}$ is 1 . Otherwise, $b_{r i j}^{n}$ is 0 .

$$
\left\{\begin{array}{l}
Y_{r i j}^{n} \leq U_{r i j}^{n} \\
Y_{r i j}^{n} \geq U_{r i j}^{n}-M\left(1-b_{r i j}^{n}\right) \\
Y_{r i j}^{n} \leq M b_{r i j}^{n} \\
Y_{r i j}^{n} \geq 0
\end{array}\right.
$$

$\left\{\begin{array}{l}X_{r i j}^{n} \leq P_{r i j n} U_{r i j}^{n} \\ X_{r i j}^{n} \geq P_{r i j n} U_{r i j}^{n}-M\left(1-b_{r i j}^{n}\right) \\ X_{r i j}^{n} \leq M b_{r i j}^{n} \\ X_{r i j}^{n} \geq 0\end{array}\right.$

$$
\left\{\begin{array}{l}
\sum_{n} b_{r i j}^{n}=1 \\
b_{r i j}^{n} \in\{0,1\}
\end{array}\right.
$$

where $P_{r i j n}$ is the main engine power when the $n$th sailing speed in calm water is selected. Eq. (47) is equivalent to $Y_{r i j}^{n}=U_{r i j}^{n} b_{r i j}^{n}$, and Eq. (48) is equivalent to $X_{r i j}^{n}=P_{r i j n} U_{r i j}^{n} b_{r i j}^{n} . M$ is a large positive constant.

Therefore, the proposed mixed-integer nonlinear optimization model for sailing speed optimization considering wind and waves is transformed into equivalent MILP, which can be solved using the commercial MILP solver CPLEX. The complete formulation is summarized below.

[MILP]

$$
\begin{aligned}
& \max \sum_{w \in W h \in H^{w}} p_{h} y_{h}-\beta \sum_{r \in R} \sum_{i \in I_{r}} \sum_{j \in I_{r}^{i}} \sum_{n} s L_{r i j} X_{r i j}^{n}-\sum_{r} C_{r}^{f i x} n_{r} \\
& -\sum_{w \in W h \in H^{w}} C_{h}^{\text {Handle }} y_{h}
\end{aligned}
$$

$$
\begin{aligned}
& \sum_{i \in I_{r}} \sum_{j \in I_{r}^{i}} \sum_{n} L_{r i j} Y_{r i j}^{n}+\sum_{w \in W h \in H^{w}} \sum_{r h} t^{\text {Handle }} y_{h}+\sum_{i \in I_{r}} t_{r i}^{P} \\
& \quad \leq 168 n_{r} \quad \forall r \in R
\end{aligned}
$$

$\sum_{h \in H^{w}} y_{h} \leq D_{w} \quad \forall w \in W$

$$
\sum_{w \in W h \in H^{w}} x_{h r i} y_{h} \leq \operatorname{Cap}_{r} \quad \forall r \in R, i \in I_{r}
$$

$$
\sum_{j \in I_{r}^{i}} \sum_{n} L_{r i j} Y_{r i j}^{n}+t_{d i}^{r} \leq T_{i+1}^{r} \quad \forall r \in R, i \in I_{r}
$$

$$
\begin{aligned}
& t_{d i+1}^{r}=\sum_{j \in I_{r}^{i}} \sum_{n} L_{r i j} Y_{r i j}^{n}+t_{d i}^{r}+\sum_{w \in W h \in H^{w}} \sum_{h r i} \delta_{r h}^{w} t^{\text {handle }} y_{h} \\
& \quad+t_{r i+1}^{p} \quad \forall r \in R, i \in I_{r} \\
& P_{r i j}=\frac{1}{2} \rho S C v_{r i j}^{2} v_{r i j}^{r} \quad \forall r \in R, i \in I_{r}, j \in I_{r}^{i} \\
& v_{r i j}^{r}=\left(v_{r i j}^{3}-2 \frac{F_{A}\left(v_{r i j}\right) v_{r i j}}{\rho S C}\right)^{\frac{1}{3}} \quad \forall r \in R, i \in I_{r}, j \in I_{r}^{i}
\end{aligned}
$$




$$
\begin{aligned}
& Y_{r i j}^{n} \leq U_{r i j}^{n} \quad \forall r \in R, i \in I_{r}, j \in I_{r}^{i}, n \in \Omega_{1} \\
& Y_{r i j}^{n} \geq U_{r i j}^{n}-M\left(1-b_{r i j}^{n}\right) \quad \forall r \in R, i \in I_{r}, j \in I_{r}^{i}, n \in \Omega_{1}
\end{aligned}
$$

$$
Y_{r i j}^{n} \leq M b_{r i j}^{n} \quad \forall r \in R, i \in I_{r}, j \in I_{r}^{i}, n \in \Omega_{1}
$$$$
Y_{r i j}^{n} \geq 0 \quad \forall r \in R, i \in I_{r}, j \in I_{r}^{i}, n \in \Omega_{1}
$$$$
X_{r i j}^{n} \leq P_{r i j n} U_{r i j}^{n} \quad \forall r \in R, i \in I_{r}, j \in I_{r}^{i}, n \in \Omega_{1}
$$$$
X_{r i j}^{n} \geq P_{r i j n} U_{r i j}^{n}-M\left(1-b_{r i j}^{n}\right) \quad \forall r \in R, i \in I_{r}, j \in I_{r}^{i}, n \in \Omega_{1}
$$

$$
X_{r i j}^{n} \leq M b_{r i j}^{n} \quad \forall r \in R, i \in I_{r}, j \in I_{r}^{i}, n \in \Omega_{1}
$$

$X_{r i j}^{n} \geq 0 \quad \forall r \in R, i \in I_{r}, j \in I_{r}^{i}, n \in \Omega_{1}$

$$
\sum_{n} b_{r i j}^{n}=1
$$

$b_{r i j}^{n} \in\{0,1\}$

$V_{\min } \leq v_{r i j} \leq V_{\max } \quad \forall r \in R, i \in I_{r}, j \in I_{r}^{i}$

$y_{h} \geq 0$

$n_{r} \in Z^{+}$

\section{Case study}

The proposed model takes the shipping network into consideration. However, to reflect the effect of the wind and waves on the sailing speed and number of containers transported, a shipping route among four ports (Lianyungang, Rizhao, Qingdao, and Sheko) is available from COSCO to assess the application of the proposed model, as shown in Fig. 2. The 4500 TEU containership is deployed on the shipping route. The detailed parameters characterizing the containership are shown in Table 2. The length and ship course of every shipping leg (including sub-shipping legs) are elaborated in Table 3. Furthermore, we assume that waves are generated by the wind and that the wave length and wave height can be estimated using the formulation proposed by Ref. [22].

\subsection{Sailing speed optimization results}

In practice, the sailing speed in calm water is determined by the main engine power. It is straightforward for a ship officer to adopt different sailing speeds in calm water by changing the rotation rate of the main engine. However, it is challenging to control the sailing speed in the wind and waves. The same rotation rate of the main engine may have a different associated sailing speed in the wind and waves, which results from different sea conditions. Therefore, the objective of sailing speed optimization is to determine the appropriate sailing speed in calm water under various sea conditions. Table 4 shows the sailing speed optimization results when the wind and waves come from the directions of $45^{\circ}, 90^{\circ}$, and $135^{\circ}$ and the wind velocity is $5 \mathrm{~m} / \mathrm{s}$, $8 \mathrm{~m} / \mathrm{s}$ and $10 \mathrm{~m} / \mathrm{s}$. The optimal sailing speed in calm water and the corresponding sailing speed in the wind and waves for various sea conditions and the scale of speed reduction are shown in Figs. 3-11.

According to Figs. 3-11, the maximum speed reduction occurs on the No. 3, No. 22 and No. 1 shipping legs when the wind and waves come from $45^{\circ}$ and the wind velocity is $5 \mathrm{~m} / \mathrm{s}, 8 \mathrm{~m} / \mathrm{s}$, and $10 \mathrm{~m} / \mathrm{s}$. The speed reductions on these shipping legs are all greater than $20 \%$. The maximum speed reduction is $36.11 \%$. The minimum speed reduction occurs on shipping leg No. 9 when the wind and waves come from $45^{\circ}$ and the wind velocity is $5 \mathrm{~m} / \mathrm{s}$ and $8 \mathrm{~m} / \mathrm{s}$. The speed reduction on the No. 5 shipping leg is minimized when the wind velocity is $10 \mathrm{~m} / \mathrm{s}$ and the wind and wave direction is $45^{\circ}$. When the wind and waves come from $90^{\circ}$ and the wind velocity is $5 \mathrm{~m} / \mathrm{s}$, $8 \mathrm{~m} / \mathrm{s}$ and $10 \mathrm{~m} / \mathrm{s}$, the maximum speed reduction occurs on the No. $2(5 \mathrm{~m} / \mathrm{s}, 8 \mathrm{~m} / \mathrm{s})$ and No. 20 shipping legs, and the minimum speed reduction occurs on the No. 12, No. 11 and No. 26 shipping legs. The maximum speed reduction is $35.18 \%$, and the minimum speed reduction is $0.21 \%$. When the wind and waves come from $135^{\circ}$ and the wind velocity is $5 \mathrm{~m} / \mathrm{s}, 8 \mathrm{~m} / \mathrm{s}$ and $10 \mathrm{~m} / \mathrm{s}$, the maximum speed reduction occurs on the No. 5 , No. 4 and No. 5 shipping legs, and the minimum speed reduction occurs on the No. $13(5 \mathrm{~m} / \mathrm{s}$ and $8 \mathrm{~m} / \mathrm{s})$ and No. 26 shipping legs, with a maximum speed reduction of $27.76 \%$ and a minimum speed reduction of $0.19 \%$.

As indicated in Table 4, different sea conditions lead to different sailing speeds adopted in calm water. With harsh sea conditions, a higher sailing speed in calm water is employed (from $11.1 \mathrm{kn}$ to $19.2 \mathrm{kn}$ when the wind velocity varies from $5 \mathrm{~m} / \mathrm{s}$ to $10 \mathrm{~m} / \mathrm{s}$ and the wind and waves come from $90^{\circ}$ ). However, higher sailing speeds in calm water are not always employed. For example, the optimal sailing speed in calm water is constant when the wind velocity varies from 5 to $8 \mathrm{~m} / \mathrm{s}$ and the wind and waves come from $45^{\circ}$, which indicates that the optimal sailing speed depends not only on the wind 


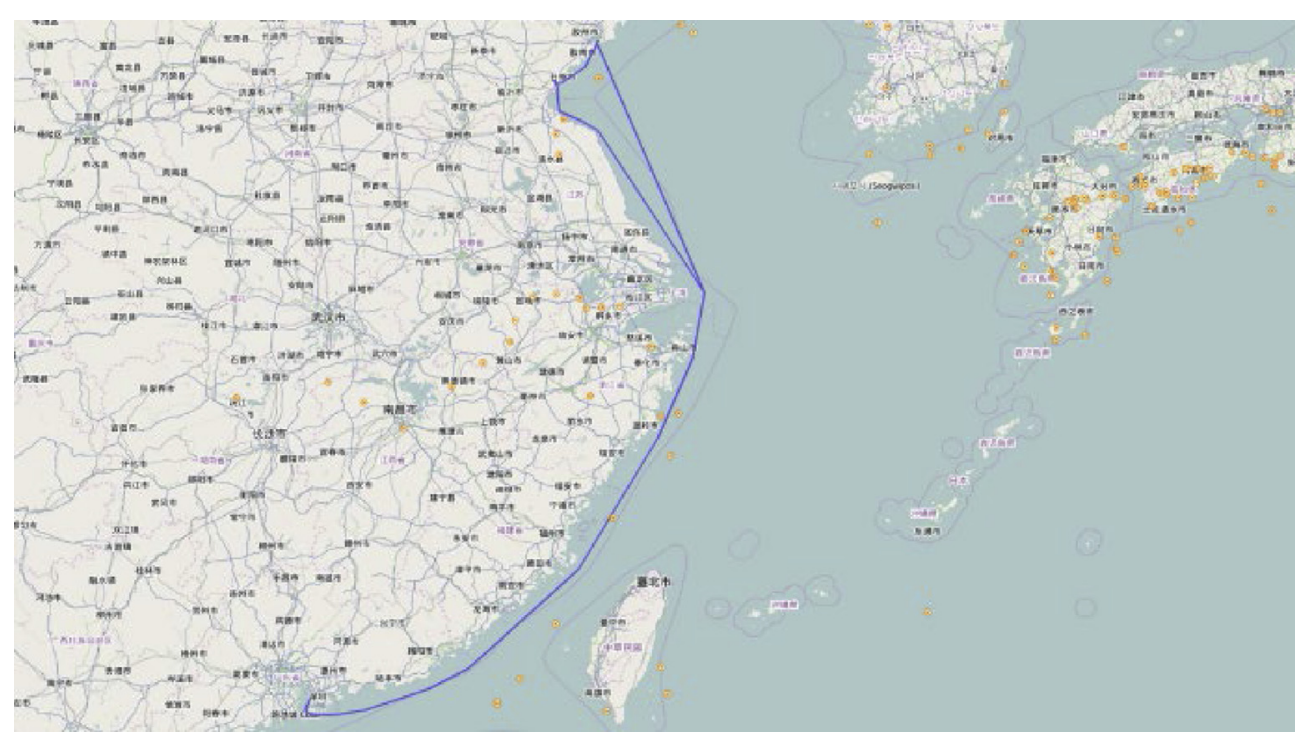

Fig. 2. Container shipping route.

Table 2. Parameters of the containership.

\begin{tabular}{llll}
\hline Ship length/L & $249.12 \mathrm{~m}$ & Longitudinal section in the centre plane & $7148.3 \mathrm{~m}^{2}$ \\
\hline Ship width/B & $37.40 \mathrm{~m}$ & Prismatic coefficient $\left(\mathrm{C}_{\mathrm{p}}\right)$ & 0.64 \\
Moulded depth/D & $22.1 \mathrm{~m}$ & Displacement & $61,614 \mathrm{t}$ \\
Draft/d & $13.5 \mathrm{~m}$ & Volume capacity & $4500 \mathrm{TEU}$ \\
Maximum speed & $24 \mathrm{kn}$ & & \\
\hline
\end{tabular}

velocity but also on the direction and ship course. However, if more thrust power is employed to help overcome the resistance caused by the wind and waves and decrease the speed reduction, the bunker consumption increases. As shown in Fig. 12, the bunker consumption considering the sea conditions is higher than the bunker consumption without considering the sea conditions, explaining why previous studies underestimated the bunker consumption.

\subsection{Optimization results for the number of containers transported}

In the application test, there are seven OD pairs (Lianyungang-Rizhao, Lianyungang-Qiangdao, Lianyungang-Sheko, Rizhao-Qingdao, Rizhao-Sheko, Qingdao-Sheko and Sheko-Lianyungang) on the shipping route. The number of containers transported between the origin port and the destination port is different when different sea conditions are

Table 3. Length and ship course of the shipping legs.

\begin{tabular}{|c|c|c|c|c|c|}
\hline Shipping leg & Distance & Ship course & Shipping leg & Distance & Ship course \\
\hline 1 & $35.81 \mathrm{n}$ mile & $353.09^{\circ}$ & 14 & $13.84 \mathrm{n}$ mile & $15.37^{\circ}$ \\
\hline 2 & 34.77 n mile & $68.10^{\circ}$ & 15 & $12.38 \mathrm{n}$ mile & $191.37^{\circ}$ \\
\hline 3 & $32.03 \mathrm{n}$ mile & $25.73^{\circ}$ & 16 & $10.88 \mathrm{n}$ mile & $153.32^{\circ}$ \\
\hline 4 & $319.04 \mathrm{n}$ mile & $156.78^{\circ}$ & 17 & $17.17 \mathrm{n}$ mile & $93.99^{\circ}$ \\
\hline 5 & $81.85 \mathrm{n}$ mile & $190.49^{\circ}$ & 18 & $46.90 \mathrm{n}$ mile & $82.39^{\circ}$ \\
\hline 6 & $105.39 \mathrm{n}$ mile & $202.09^{\circ}$ & 19 & $92.64 \mathrm{n}$ mile & $68.98^{\circ}$ \\
\hline 7 & 197.41 n mile & $210.16^{\circ}$ & 20 & $56.53 \mathrm{n}$ mile & $61.75^{\circ}$ \\
\hline 8 & 179.32 n mile & $227.01^{\circ}$ & 21 & $177.57 \mathrm{n}$ mile & $45.50^{\circ}$ \\
\hline 9 & $57.10 \mathrm{n}$ mile & $241.02^{\circ}$ & 22 & $200.01 \mathrm{n}$ mile & $29.30^{\circ}$ \\
\hline 10 & $89.97 \mathrm{n}$ mile & $249.75^{\circ}$ & 23 & $104.29 \mathrm{n}$ mile & $21.96^{\circ}$ \\
\hline 11 & $48.10 \mathrm{n}$ mile & $262.90^{\circ}$ & 24 & $81.63 \mathrm{n}$ mile & $9.57^{\circ}$ \\
\hline 12 & $17.12 \mathrm{n}$ mile & $270.05^{\circ}$ & 25 & $228.95 \mathrm{n}$ mile & $328.36^{\circ}$ \\
\hline 13 & $11.49 \mathrm{n}$ mile & $327.83^{\circ}$ & 26 & $48.18 \mathrm{n}$ mile & $298.42^{\circ}$ \\
\hline
\end{tabular}


Table 4. Sailing speed optimization results. Unit: $k n$.

\begin{tabular}{|c|c|c|c|c|c|c|c|c|}
\hline \multirow[t]{2}{*}{ No. } & $45^{\circ}$ & & & \multicolumn{3}{|l|}{$90^{\circ}$} & \multicolumn{2}{|l|}{$135^{\circ}$} \\
\hline & $5 \mathrm{~m} / \mathrm{s} 8 \mathrm{~m} / \mathrm{s} 10 \mathrm{~m}$ & $8 \mathrm{~m} / \mathrm{s}$ & $10 \mathrm{r}$ & $5 n$ & $8 n$ & $10 n$ & $5 \mathrm{~m} / \mathrm{s}$ & $8 \mathrm{~m}$ \\
\hline 1 & 11.3 & 11.3 & 11.3 & 11.1 & 11.1 & 11.1 & 11.1 & 11.111 .1 \\
\hline ? & 11.2 & 11.8 & 12.4 & 11.2 & 11.8 & 12.4 & 11.1 & 11.211 .2 \\
\hline 3 & 11.1 & 11.7 & 12.3 & 11.1 & 11.1 & 11.1 & 11.1 & 11.111 .1 \\
\hline 4 & 11.1 & 11.1 & 11.1 & 11.1 & 11.1 & 11.1 & 11.4 & 11.622 \\
\hline 5 & 11.1 & 11.1 & 11.1 & 11.1 & 11.1 & 11.1 & 11.1 & 11.611 .6 \\
\hline 6 & 11.1 & 11.1 & 11.1 & 11.1 & 11.1 & 11.1 & 11.1 & 11.111 .1 \\
\hline 7 & 11.1 & 11.1 & 11.1 & 11.1 & 11.1 & 11.1 & 11.1 & 11.111 .1 \\
\hline 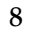 & 11.1 & 11.1 & 11.1 & 11.1 & 11.1 & 19.2 & 19.2 & 19.219 .2 \\
\hline y & 18.5 & 18.5 & 18.5 & 18.5 & 18.5 & 18.5 & 18.5 & 18.518 .5 \\
\hline 10 & 17.8 & 17.8 & 17.8 & 17.8 & 17.8 & 17.8 & 17.8 & 17.817 .8 \\
\hline 11 & 17.1 & 17.1 & 17.1 & 17.1 & 17.1 & 17.1 & 17.1 & 17.117 .1 \\
\hline 12 & 16.4 & 16.4 & 16.4 & 16.4 & 16.4 & 16.4 & 16.4 & 16.416 .4 \\
\hline 13 & 15.7 & 15.7 & 15.7 & 15.7 & 15.7 & 15.7 & 15.7 & 15.715 .7 \\
\hline 14 & 15 & 15 & 15 & 15 & 15 & 15 & 15 & $15 \quad 15$ \\
\hline 15 & 14.3 & 14.3 & 14.3 & 14.3 & 14.3 & 14.3 & 14.3 & 14.314 .3 \\
\hline 16 & 13.6 & 13.6 & 13.6 & 13.6 & 13.6 & 13.6 & 13.6 & 13.613 .6 \\
\hline 17 & 12.9 & 12.9 & 13.1 & 12.9 & 12.9 & 13.1 & 12.9 & $13 \quad 13.1$ \\
\hline 18 & 12.2 & 12.4 & 12.4 & 12.2 & 12.4 & 12.4 & 12.2 & 12.412 .4 \\
\hline 19 & 11.7 & 11.7 & 12.3 & 11.7 & 11.7 & 12.3 & 11.5 & 11.611 .7 \\
\hline 20 & 11.6 & 11.6 & 12.2 & 11.6 & 11.6 & 12.2 & 11.1 & 11.111 .1 \\
\hline 21 & 11.5 & 11.5 & 12.1 & 11.5 & 11.5 & 12.1 & 11.1 & 11.111 .1 \\
\hline 22 & 11.4 & 11.4 & 12 & 11.1 & 11.4 & 11.4 & 11.1 & 11.111 .1 \\
\hline 23 & 11.3 & 12 & 21.7 & 11.1 & 11.1 & 11.1 & 11.1 & 11.111 .1 \\
\hline 24 & 11.3 & 21 & 21 & 11.1 & 11.1 & 11.1 & 11.1 & 11.111 .1 \\
\hline 25 & 24 & 24 & 24 & 24 & 24 & 24 & 24 & $24 \quad 24$ \\
\hline 26 & 24 & 24 & 24 & 24 & 24 & 24 & 24 & $24 \quad 24$ \\
\hline
\end{tabular}

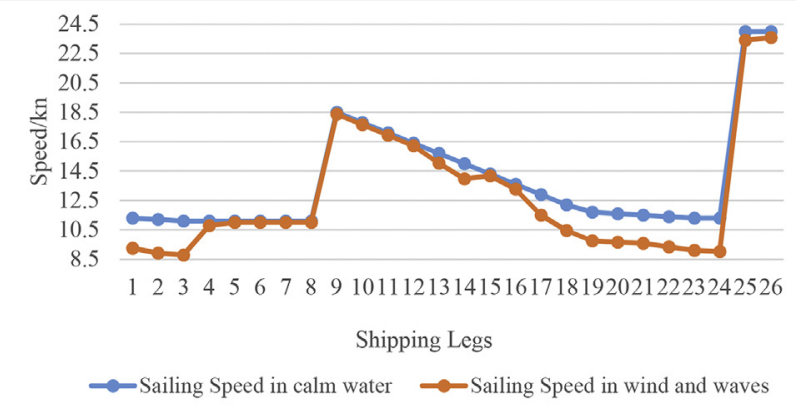

(a) Sailing speed in calm water and in the wind and waves

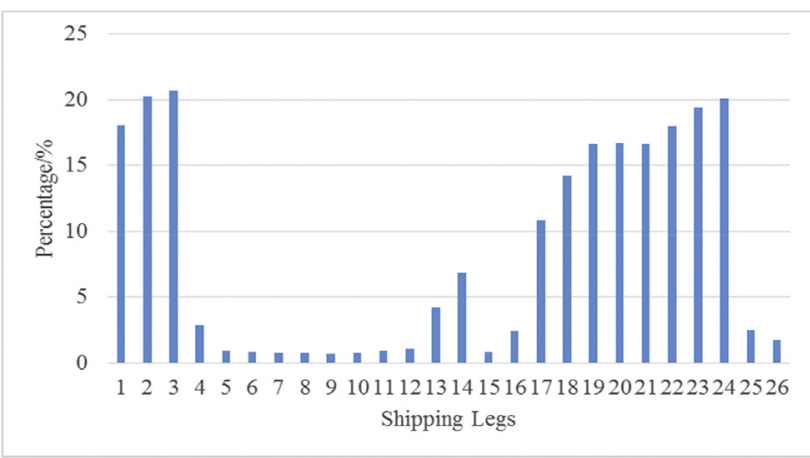

(b) Scale of speed reduction

Fig. 3. Wind and waves coming from $45^{\circ}$; the wind velocity is $5 \mathrm{~m} / \mathrm{s}$.

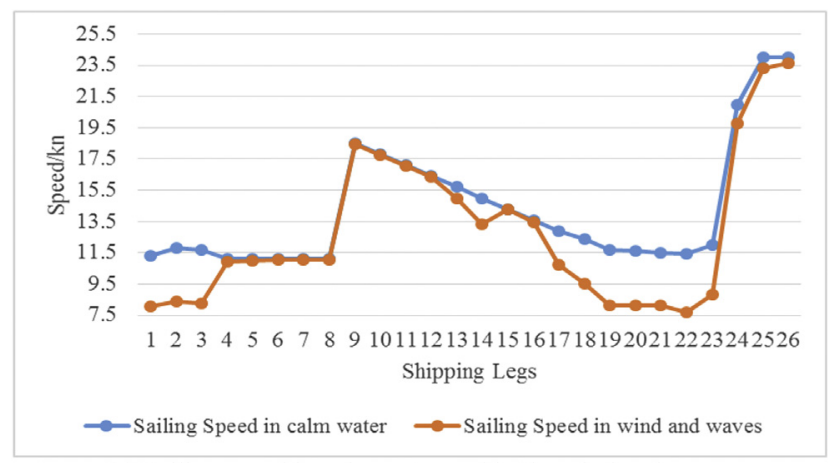

(a) Sailing speed in calm water and in the wind and waves

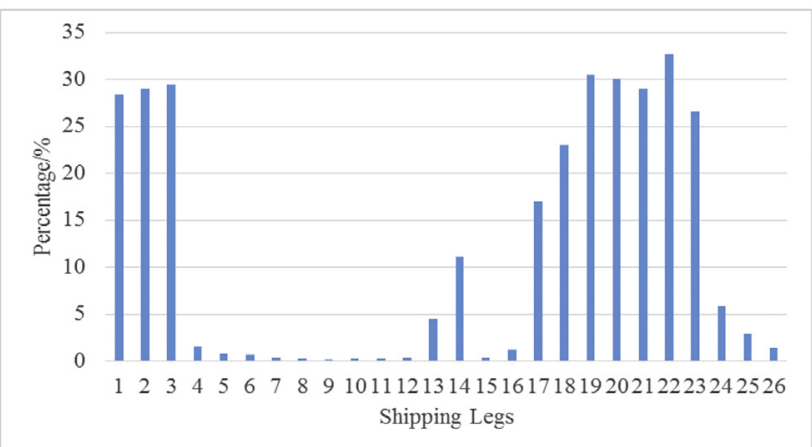

(b) Scale of speed reduction

Fig. 4. Wind and waves coming from $45^{\circ}$; the wind velocity is $8 \mathrm{~m} / \mathrm{s}$.

encountered (see Fig. 13). Therefore, the wind and waves can also have an influence on the container assignments. When shipping legs have a long distance and more thrust power is employed for

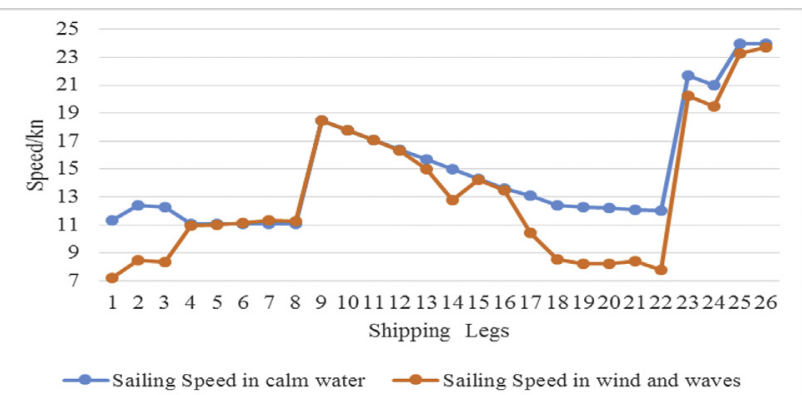

(a) Sailing speed in calm water and in the wind and waves

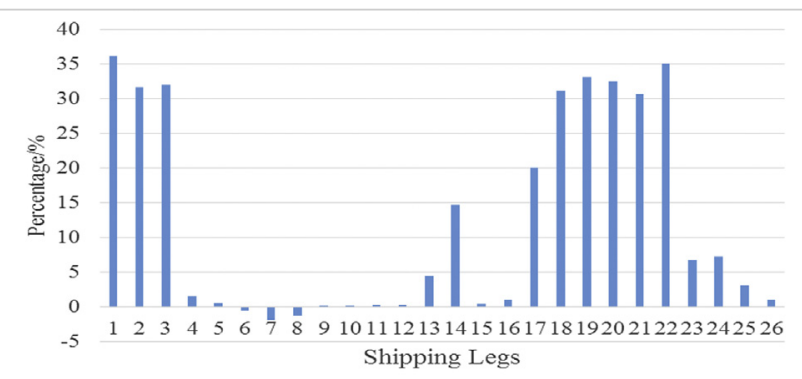

(b) Scale of speed reduction

Fig. 5. Wind and waves coming from $45^{\circ}$; the wind velocity is $10 \mathrm{~m} / \mathrm{s}$. 


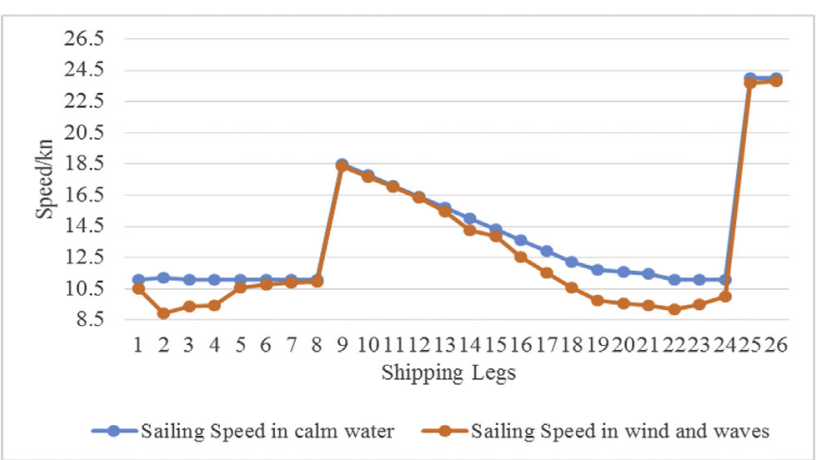

(a) Sailing speed in calm water and in the wind and waves

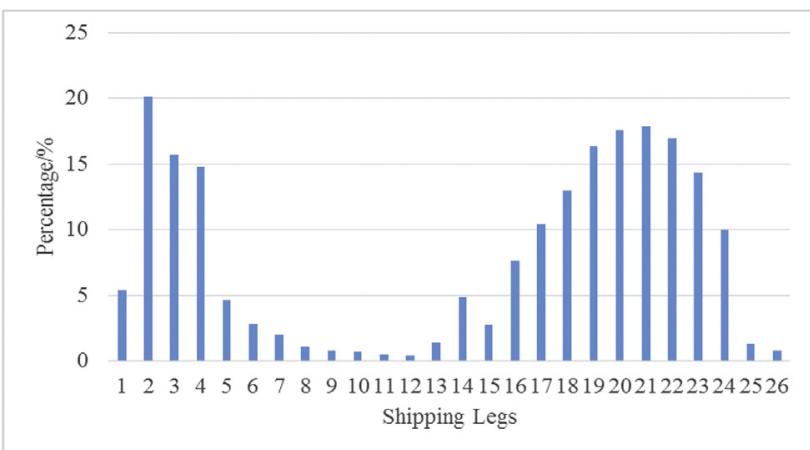

(b) Scale of speed reduction

Fig. 6. Wind and waves coming from $90^{\circ}$; the wind velocity is $5 \mathrm{~m} / \mathrm{s}$.

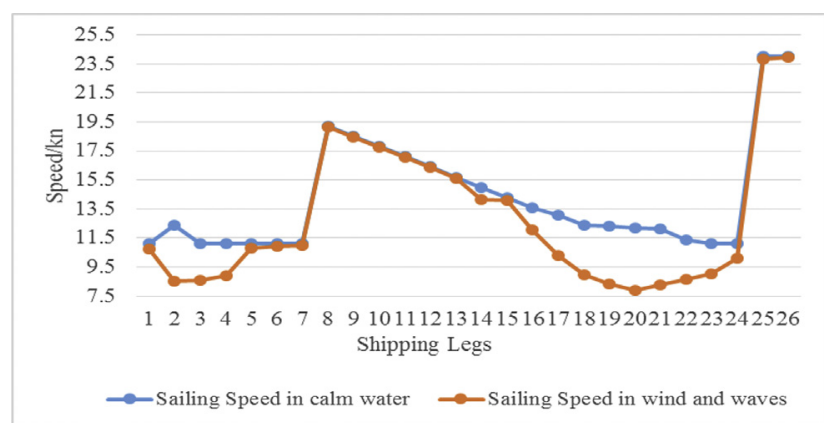

(a) Sailing speed in calm water and in the wind and waves

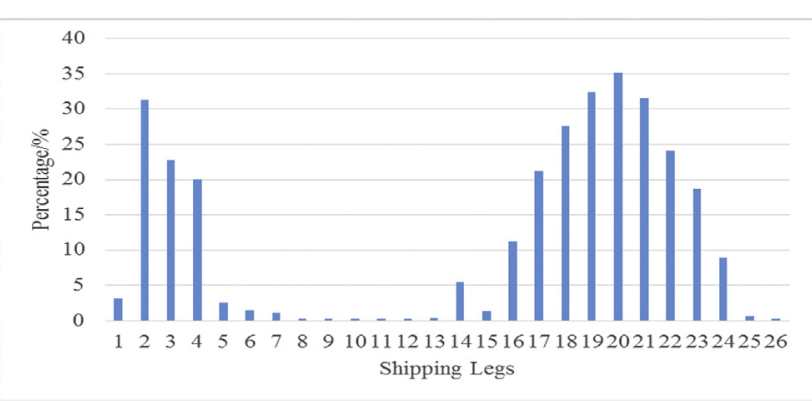

(b) Scale of speed reduction

Fig. 8. Wind and waves coming from $90^{\circ}$; the wind velocity is $10 \mathrm{~m} / \mathrm{s}$.

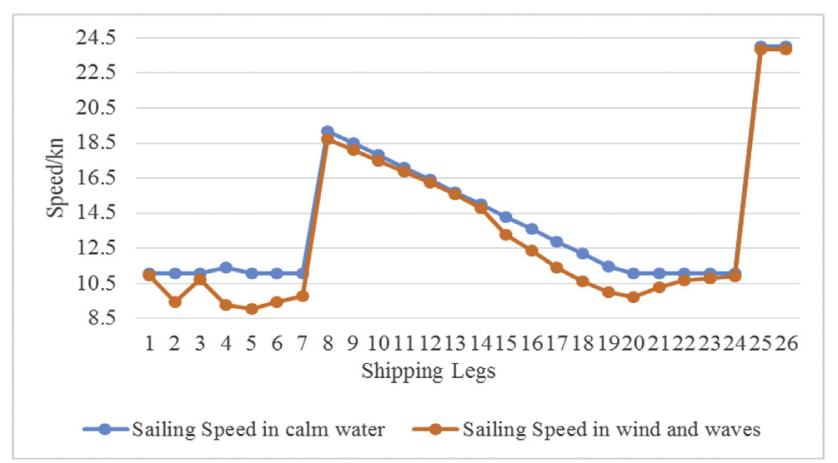

(a) Sailing speed in calm water and in the wind and waves

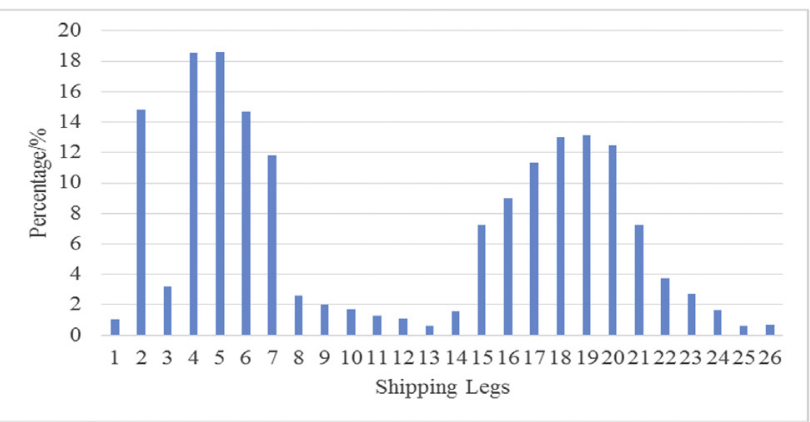

(b) Scale of speed reduction

Fig. 9. Wind and waves coming from $135^{\circ}$; the wind velocity is $5 \mathrm{~m} / \mathrm{s}$.

Fig. 7. Wind and waves coming from $90^{\circ}$; the wind velocity is $8 \mathrm{~m} / \mathrm{s}$. 


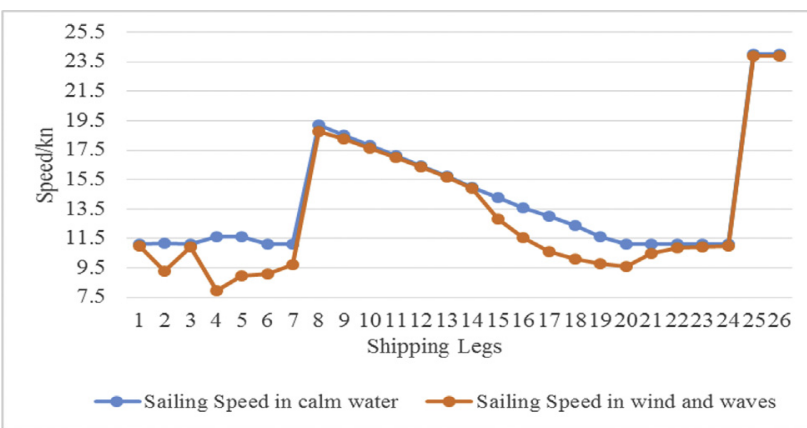

(a) Sailing speed in calm water and in the wind and waves

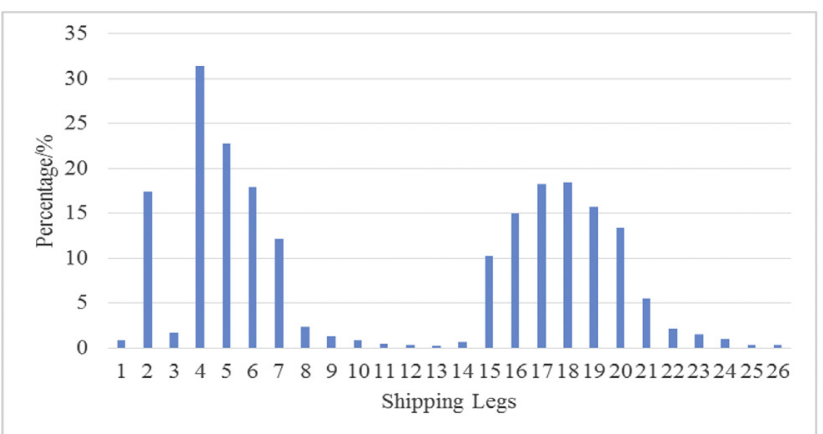

(b) Scale of speed reduction

Fig. 10. Wind and waves coming from $135^{\circ}$; the wind velocity is $8 \mathrm{~m} / \mathrm{s}$.

overcoming speed reduction, more containers are transported.

Furthermore, the objective of the proposed model is to maximize profit. To achieve this objective, the container shipping company must transport more containers on these shipping legs if the container

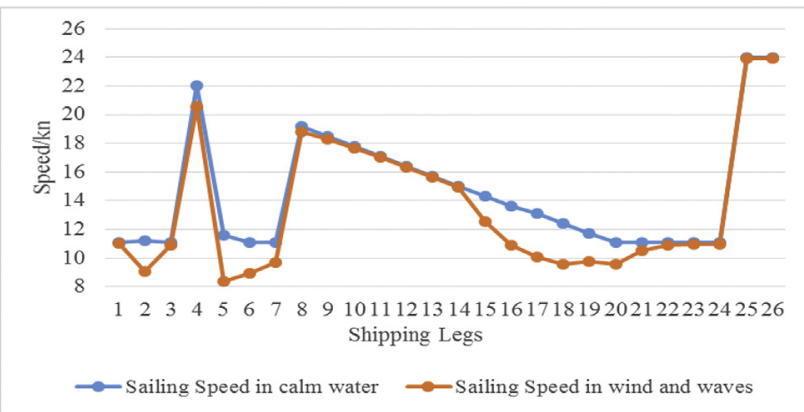

(a) Sailing speed in calm water and in the wind and waves

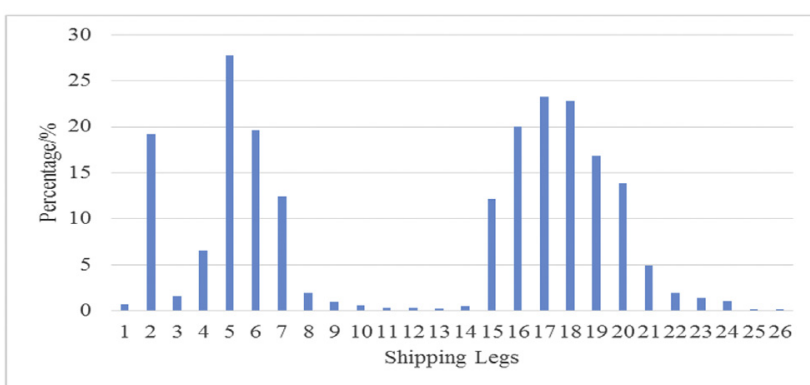

(b) Scale of speed reduction

Fig. 11. Wind and waves coming from $135^{\circ}$; the wind velocity is $10 \mathrm{~m} / \mathrm{s}$. quantity does not violate the capacity of the containership deployed on the shipping route. However, sea conditions have less influence on the number of containers transported on the shipping legs that have a short distance and for which the ship course is varied. We also find that the number

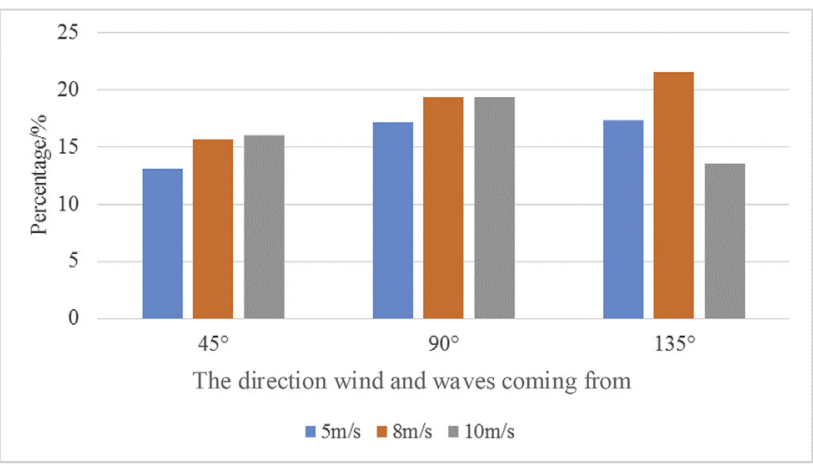

Fig. 12. Comparison of fuel consumption without considering the sea conditions.

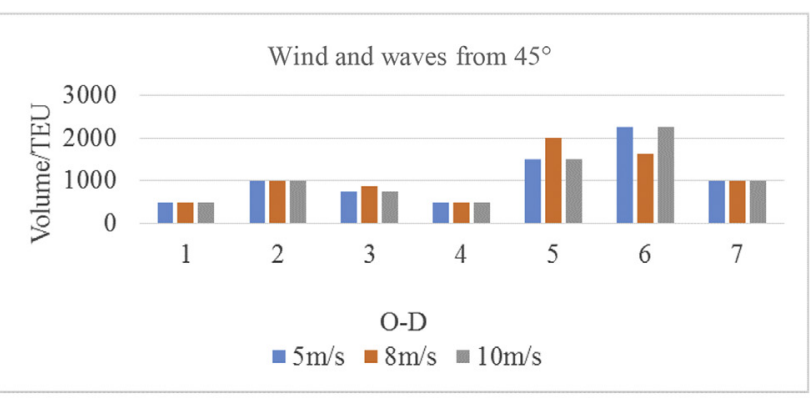

(a) Wind and waves coming from $45^{\circ}$

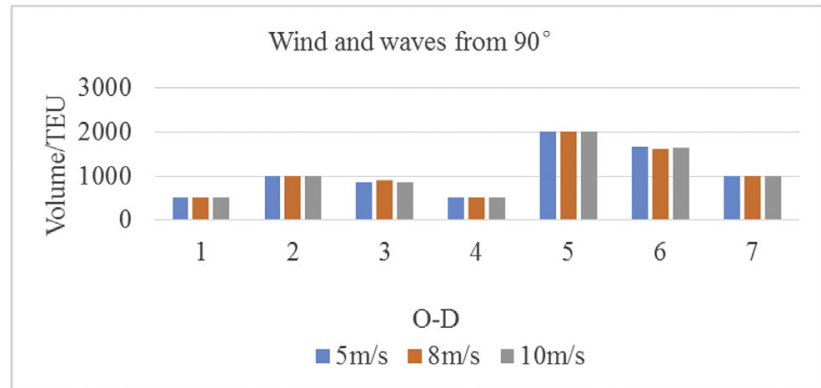

(b) Wind and waves coming from $90^{\circ}$

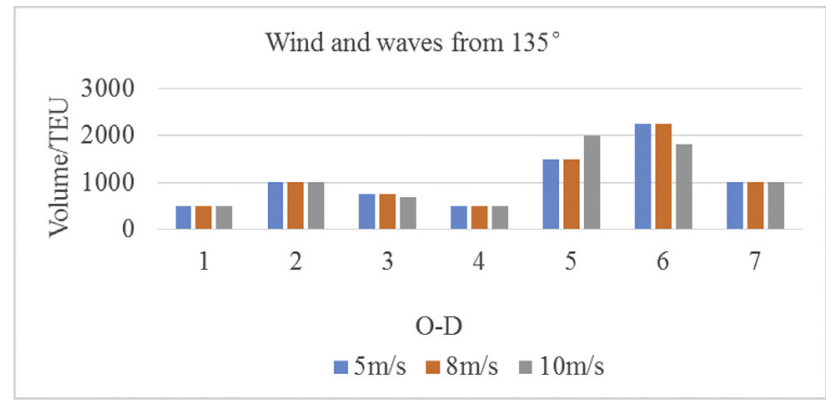

(c) Wind and waves coming from $135^{\circ}$

Fig. 13. Optimization results for the number of containers transported. 
of containers transported from Sheko to Lianyungang is constant because it is the last shipping leg on the shipping route. To avoid sailing in ballast and maximize profit, it is favourable to transport more containers.

\section{Conclusions}

This study has proposed the liner sailing speed optimization problem considering wind and waves to maximize the profit of a container liner shipping company given sea conditions and weekly shipment demand. With the total profit calculated as the freight revenue minus the operating costs composed of the container handling cost, bunker consumption cost and fleet operation cost, the optimal decision measures are achieved, including the number of containers and containership assignment on the shipping route and ship sailing speed determination on each shipping leg. As the bunker consumption function and some constraints are nonlinear, the sailing speed optimization problem considering wind and waves is defined as a MINLP model. An equivalent MILP model has been developed to transform MINLP into MILP. The case study reveals that the model can be solved efficiently with the proposed method to obtain the optimal solution under various sea conditions. Furthermore, container assignments are also affected by the wind and waves. This study not only fills the gap between theory and practice but also applies a useful support tool to help liner shipping companies determine appropriate measures to maximize profit.

\section{Acknowledgements}

This research work was supported by the National Key Research and Development Program of China (2017YFC0805309), the National Natural Science Foundation of China (71901005) and the Social Science Program of Beijing Municipal Education Committee (SM202010011008).

\section{References}

[1] Aydin N, Lee H, Mansouri SA. Speed optimization and bunkering in liner shipping in the presence of uncertain service times and time windows at ports. Eur J Oper Res 2017;259(1):143-54.

[2] Corbett JJ, Wang H, Winebrake JJ. The effectiveness and costs of speed reductions on emissions from international shipping. Transport Res D 2010;14:593-8.

[3] Christiansen M, Fagerholt K, Ronen D. Ship routing and scheduling: status and perspectives. Transport Sci 2004;38(1): $1-18$.

[4] Du Y, Chen Q, Quan X, Long L, Fung RYK. Berth allocation considering fuel consumption and vessel emissions. Transport Res Part E 2011;47(6):1021-37.
[5] Daidola JC. A simulation program for vessel's manoeuvring at slow speeds. In: Proceeding of eleventh ship technology and research symposium; 1986.

[6] Fagerholt K, Laporte G, Norstad I. Reducing fuel emissions by optimizing speed on shipping routes. J Oper Res Soc 2010; 61(3):523-9.

[7] Golias MM, Saharidis GK, Boile M, Theofanis S, Ierapetritou MG. The berth allocation problem: optimizing vessel arrival time. Marit Econ Logist 2009;11:358-77.

[8] Gelareh S, Nickel S, Pisinger D. Liner shipping hub network design in a competitive environment. Transport Res 2010;46: 991-1004.

[9] Gelareh S, Pisinger D. Fleet deployment, network design and hub location of liner shipping companies. Transport Res 2011;47:947-64.

[10] Hvattum LM, Norstad I, Fagerholt K, Laporte G. Analysis of an exact algorithm for the vessel speed optimization problem. Networks 2013;62(2):132-5.

[11] Isherwood RM. Wind resistance of merchant ships. R Inst Nav Archit 1972;114:327-38.

[12] Jiang WQ. Ship theory. Dalian: Dalian Maritime University; 1997.

[13] Kim H-J, Kim J-G. A heuristic algorithm for determining the speed and bunkering port of a ship considering green house gas emissions. In: Proceedings of the Asia Pacific industrial engineering \& management systems conference; 2012.

[14] Lee H, Aydin N, Choi Y, Lekhavat S, Irani Z. A decision support system for vessel speed decision in maritime logistics using weather archive big data. Comput Oper Res 2018, 98:330-42.

[15] Li C, Qi X, Song D. Real-time schedule recovery in liner shipping service with regular uncertainties and disruption events. Transport Res Part B 2016;93:762-88.

[16] Meng $Q$, Wang T. A chance constrained programming model for short-term liner ship fleet planning problems. Marit Pol Manag 2010;37(4):329-46.

[17] Meng Q, Wang S. Liner shipping service network design with empty container repositioning. Transport Res 2011;47: 695-708.

[18] Meng Q, Wang T. A scenario-based dynamic programming model for multi-period liner ship fleet planning. Transport Res 2011;47:401-13.

[19] Meng Q, Wang S. Optimal operating strategy for a long-haul liner service route. Eur J Oper Res 2011;215:105-14.

[20] Notteboom TE, Vernimmen B. The effect of high fuel costs on liner service configuration in container shipping. J Transport Geogr 2009;17(5):325-37.

[21] Norstad I, Fagerholt K, Laporte G. Tramp ship routing and scheduling with speed optimization. Transport Res Part C 2011;19(5):853-65.

[22] Price WS, Bishop RED. Probabilistic theory of ship dynamic. London: Chapmann and Hall Ltd; 1974.

[23] Qi X, Song DP. Minimizing fuel emissions by optimizing vessel schedules in liner shipping with uncertain port times. Transport Res Part E 2012;48(4):863-80.

[24] Ronen D. The effect of oil price on containership speed and fleet size. J Oper Res Soc 2011;62(1):211-6.

[25] Ronen D. The effect of oil price on the optimal speed of ships. J Oper Res Soc 1982;33:1035-40.

[26] Shen X, Chew EP, Lee LH. $(s, S)$ policy model for liner shipping refueling and sailing speed optimization problem. Transport Res Part E 2015;76:76-92.

[27] Shintani K, Imai A, Nishimura E, Papadimitriou S. The container shipping network design problem with empty container repositioning. Transport Res 2007;43:39-59.

[28] UNCTAD. Review of maritime transportation. In: Paper presented at the United Nations conference on trade and development, New York and Geneva; 2016.

[29] Wang S, Meng Q. Liner ship route schedule design with sea contingency time and port time uncertainty. Transport Res Part B 2012;46(5):615-33.

[30] Wang S, Meng Q. Robust schedule design for liner shipping services. Transport Res Part E 2012;48(6):1093-106. 
[31] Wang S, Meng Q. Sailing speed optimization for container ships in a liner shipping network. Transport Res Part E 2012; 48(3):701-14.

[32] Wang S, Meng Q, Liu Z. A note on berth allocation considering fuel consumption and vessel emissions. Transport Res Part E 2013;49(1):48-54.

[33] Wang S, Meng Q. Robust bunker management for liner shipping networks. Eur J Oper Res 2015;24(3):789-97.

[34] Wang Y, Meng Q, Du Y. Liner container seasonal shipping revenue management. Transport Res Part B 2015;82:141-61.
[35] Wang S, Meng Q. Schedule design and container routing in liner shipping. Transport Res Rec 2011;2222:25-33.

[36] Wang S, Wang T, Meng Q. A note on liner ship fleet deployment. Flex Serv Manuf J 2011;23:422-30.

[37] Wang S, Meng Q. Liner ship fleet deployment with container transshipment operations. Transport Res Part E 2012;48: 470-84.

[38] Yao Z, Ng SH, Lee LH. A study on bunker fuel management for the shipping liner services. Comput Oper Res 2012;39(5): 1160-72. 